\title{
Considerações históricas, estruturais e características sobre o instrumento Sixxen, de Iannis Xenakis ${ }^{1}$
}

\author{
Historical, Structural and Characteristic Considerations \\ on Iannis Xenakis's Sixxen Instrument
}

\author{
Ronan Gil de Morais \\ Instituto Federal de Goiás, Goiânia-GO \\ ronangil@gmail.com
}

\section{Fernando Martins de Castro Chaib}

Universidade Federal de Minas Gerais, Belo Horizonte-MG

fernandochaib@gmail.com

\author{
Fabio Fonseca de Oliveira \\ Universidade Federal de Goiás, Goiânia-GO \\ oliveira.ff@gmail.com
}

\begin{abstract}
Resumo: A busca dos compositores por novas possibilidades sonoras e materiais específicos impulsionou a pesquisa e o desenvolvimento de novos instrumentos de percussão. Delineamos e discutimos definições, aspectos históricos e características estruturais de construção do instrumento denominado Sixxen. Concebido por Iannis Xenakis, este instrumento vem ampliando consideravelmente seu repertório através da produção de compositores como Phillipe Manoury, Michelle Agnes, dentre outros. Relativamente aos aspectos históricos apresentamos pontos que caracterizaram o primeiro modelo desenvolvido juntamente entre Xenakis e o Les Percussions de Strasbourg. Expomos uma revisão dos tipos de Sixxen construídos por diversos grupos de distintos países, além de quatro empresas que já desenvolveram modelos para comercialização. Trazemos assim uma extensa documentação sobre a criação de um importante instrumento do séc. XX.
\end{abstract}

Palavras-chave: Sixxen; Pléïades de Iannis Xenakis;. desenvolvimento de instrumentos musicais; organologia de metalofones.

\begin{abstract}
The composers' search for new sound possibilities and specific timbers boosted the research and development of new percussion instruments. This article seeks to outline and discuss the definition, historical and structural aspects, diffusion and repertoire composed for Sixxen. Conceived by Iannis Xenakis, this instrument has considerably expanded its repertoire through the work of composers such as Phillipe Manoury, Michelle Agnes, among others. With regard to the historical aspects, we present points that characterized the creation of the first set of Sixxen, developed by Xenakis and Les percussions de Strasbourg. We present a review of the Sixxen sets built by various groups around the World, in addition to four companies that have developed commercial prototypes. This paper will bring an extensive documentation on an important instrumental creation of the 20 th century.
\end{abstract}

Keywords: Sixxen; Pléïades by Iannis Xenakis; development of musical instruments; organology of metallophones.

Data de recebimento: 20 January 2017

Data de aprovação final: 8 May 2018

\footnotetext{
${ }^{1}$ Trabalho realizado pelo Núcleo de Excelência para o Ensino, Pesquisa e Performance em Percussão - N三P , com o apoio financeiro do CNPq/SEC/MinC e PROAPP/IFG.
} 


\title{
1. Introdução
}

A obra Pléïades foi composta entre 1978-79 e trata-se da segunda colaboração direta entre o compositor Iannis Xenakis com o grupo Les Percussions de Strasbourg - sendo a primeira, Persephassa (1969). Dez anos depois da primeira composição para o sexteto, Xenakis propõe uma obra de grandes proporções (com cerca de uma hora de duração), sendo sua mais longa obra instrumental depois de Kraanerg, com 74 minutos de duração (HARLEY, 2004, p.109). Pléïades é dividida em quatro movimentos (Peaux, Métaux, Claviers e Mélanges) sendo uma obra marco e referencial para a percussão, como em geral é toda a obra de Xenakis para percussão. Os quatro movimentos podem ser tocados em ordens variadas, havendo algumas sequências prévias sugeridas pelo compositor. Xenakis utiliza para esta composição basicamente três grupos de instrumentos: tambores, instrumentos de teclado (3 vibrafones, marimba, xilorimba e xilofone) e um instrumento de metal até então impensado, o Sixxen. Dos quatro movimentos, três foram escritos para apenas um grupo de instrumentos: Peaux exclusivamente para peles; Claviers para teclados de percussão; Métaux somente para Sixxen. 0 4ํ movimento, Mélanges, (do francês 'misturas') é o único com associação tímbrica entre instrumentos de naturezas distintas, utilizando os três timbres anteriores simultaneamente. Para mais informações sobre questões analíticas específicas sobre Pléïades pode-se consultar LACROIX (2001) que faz uma contextualização histórica e analisa o movimento Claviers, HARLEY (2004) que faz uma análise mais ampla da obra correlacionando-a com outras obras de Xenakis e MARANDOLA (2012) que faz uma análise interpretativa do movimento Peaux. Para mais detalhes sobre as teorias composicionais que Xenakis utiliza nesta obra é preciso consultar seu livro Kéleütha sobre a Teoria dos Crivos (XENAKIS, 1994, p.75-87).

A obra Pléïades (1978-79) foi comissionada para ser estreada com balé e conforme o site do Les percussions de Strasbourg:

\begin{abstract}
Iannis Xenakis (nascido em 1922) compôs «Pléiades " ao longo dos anos 1978-79 como uma comissão da cidade de Strasbourg. Esta peça foi tocada pela primeira vez pelo Les Percussions de Strasbourg quando de um concerto com o Ballet du Rhin no dia 3 de maio de 1979. 0 título Pléiades faz referência aos seis membros do Les Percussions de Strasbourg. Mas, para Xenakis, a referência à multiplicidade da existência parece mais importante (LES PERCUSSIONS DE STRASBOURG, s.d., s.p.)22.
\end{abstract}

Nos Estados Unidos, a obra teve sua primeira audição em 10 de novembro de 1981 pelo Oberlin Percussion Group, no Oberlin College sob a direção de Michael Rosen, que contou com a presença de Xenakis na plateia (NEWS, 1982, p.15). No Canadá foi a vez do grupo Nexus, que também trabalhou diretamente com o compositor no início da década de 80 (ENGELMAN, 2010, s.p.).

A construção do instrumento Sixxen (cujo nome registra e eterniza o compositor e o grupo de Strasbourg: Six, seis em inglês em menção ao sexteto de percussão; e Xen, de Xenakis) é assim uma condição sine qua non para a execução completa da obra. Em 2018, a composição de Pléïades e a concepção do Sixxen farão 40 anos, mesmo assim algumas informações carecem de

2 Todas as citações são traduções livres dos autores deste artigo. 
atenção e registro. Muitos percussionistas, musicólogos, teóricos, estetas e historiadores musicais trabalham na pesquisa e análise de referenciais teóricos e práticos sobre a obra de Iannis Xenakis. Contudo, nenhum trabalho se dedicou exclusivamente à coleta de dados, formalização e discussão sobre o panorama do Sixxen na atualidade. Percebe-se ser bastante vaga a compreensão dos aspectos históricos que caracterizaram a construção do primeiro Sixxen e a relação de Xenakis com o Les Percussions de Strasbourg. Também não existem na literatura, por exemplo, quaisquer informações que deem conta de quantos protótipos foram desenvolvidos nesses quase 40 anos de obra. Uma vez existentes, não há um material que nos indique onde esses Sixxens foram construídos e por quem utilizados. Tão pouco existem dados que ilustrem as características físicas e sonoras desses instrumentos (forma, material utilizado, timbre, ressonância, amplitude e frequência) uma vez que, apesar de indicar certos preceitos, Xenakis deixa em aberto os meios para concepção e construção dos mesmos.

Assim, com o intuito de discutir um panorama histórico e de difusão, bem como as características ontológicas e estruturais do instrumento, o presente artigo aborda o objeto de estudo através de revisão bibliográfica e documental ampla (registros fonográficos e fotográficos, mídias digitais, fontes e arquivos diversos) para tecer uma compreensão sobre a relevância do instrumento na história dos sécs. XX e XXI.

\title{
2. Sixxen, a definição xenakiana e os fundamentos conceituais sobre o instrumento
}

Na primeira página da grade completa de Pléiades (1978-79), Xenakis aborda algumas questões sobre o Sixxen:

\begin{abstract}
A segunda tentativa foi de ter um novo instrumento metálico construído, chamado de SIX-XEN, compreendendo dezenove alturas irregularmente distribuídas com distância de quartos de tons ou terços de tons ou seus múltiplos. Além disso, as seis cópias dos instrumentos tomadas como um todo nunca deve produzir uníssono. Quanto à primeira questão, após inúmeras tentativas eu construí uma série (escala) que, surpresa! , tinha semelhanças com as escalas da Grécia antiga, do Oriente Médio ou da Indonésia. No entanto a minha escala, ao contrário dessas escalas tradicionais, não se baseia na oitava; possui simetrias internas e consegue cobrir o espaço cromático total em três cópias consecutivas (períodos), permitindo assim criar, por si só, sem transposições, campos harmônicos suplementares quando superposições polifônicas são feitas (XENAKIS, 1978, p.1).
\end{abstract}

Percebe-se, assim, que Xenakis descreve de modo muito sucinto e com poucas especificações estruturais a maneira como este conjunto instrumental deve ser construído. As pouquíssimas indicações do compositor para descrição do instrumento deixam inúmeras possibilidades de interpretação. Em texto mais específico, presente na primeira página das partituras individuais do movimento Métaux, observa-se: 
Utilizar 19 peças de metal de timbres vizinhos e escalonar do ponto de vista das alturas. As 19 alturas não deverão formar relações cromáticas ou diatônicas temperadas. As peças deverão soar desajustadas entre elas. 0 âmbito das 19 alturas é arbitrário e dependerá das peças disponíveis; mas ele será o mesmo para os seis percussionistas e localizado no mesmo registro. Isto significa que para uma altura dada, as 6 peças de metal darão somente de maneira aproximada a altura; é até mesmo recomendado que estas 6 notas, tomadas duas a duas, não estejam em uníssono, a distância podendo compreender entre mais ou menos 3/4 de tom. As alturas são notadas cromaticamente [tendo-se como base a Clave de Sol, do Fá 3 ao Si 5] mas elas não têm nenhuma relação com as alturas reais (XENAKIS, 1978, p.1 - partitura individual do movimento Métaux).

Assim, percebe-se nas suas considerações a peculiaridade de um "instrumento" afinado com sutis diferenças microtonais mas que é concebido como um conjunto instrumental. O Sixxen deve ser construído em seis partes que tenham afinações ligeiramente próximas e relativamente desajustadas entre si, fazendo soar atritos de frequências em função das diferenças de cada um dos seis jogos de 19 alturas.

Por outro lado, Xenakis deixa uma série de elementos a critério dos construtores, entre os quais: a escolha do material metálico a ser utilizado, o timbre e afinação final de cada lâmina, as escalas resultantes das notas desejadas para cada instrumento, o tamanho das lâminas e do corpo do instrumento, a disposição das notas, a maneira como cada nota será apoiada ao corpo do instrumento, a presença de mecanismo de abafamento das lâminas, a necessidade de estruturas anexas como ressonadores ou outros. Ainda assim, segundo REED (2003, p.48), baseado na amostragem das gravações disponíveis de Pléïades, as instruções de construção dadas por Xenakis produzem instrumentos com similaridade suficiente para serem reconhecidos como um só tipo de instrumento, ainda que cada um reflita uma identidade sonora própria. MANOURY (2012) corrobora com esta afirmação ao mencionar que:

Pode-se imaginar que diferentes jogos de Sixxens podem soar diferentes (o que aliás é a realidade pois, como eu expliquei, estes instrumentos não são estandardizados) ainda resguardando uma estrutura musical que guardará sua coerência formal qualquer que seja a natureza das alturas que a comporá. (MANOURY, 2012, s.p.).

Manoury que, para a criação de suas próprias peças, analisou o protótipo aceito por Xenakis, faz algumas considerações sobre os anseios de Xenakis:

0 que quer que seja [um instrumento como o Sixxen], no estado atual de conhecimento, podemos afirmar várias coisas. Primeiramente, que a natureza assaz inarmônica de seus sons torna difícil toda exatidão com relação aos quartos de tom que Xenakis desejava. A 'inarmonicidade', como se sabe, distancia a sensação de altura fundamental. Estes instrumentos são compostos de 19 lâminas e multiplicadas por grupos de seis (de onde vem seu nome six $=6$ e xen $=$ Xenakis) e deveriam «teoricamente » ser «afinados» em 
uma escala de terça menor, o segundo sixxen soando um quarto de tom acima do primeiro, o terceiro um quarto de tom acima do segundo, etc. 0 âmbito total, considerando-se a primeira nota do primeiro sixxen (a mais grave) até a última nota do sexto sixxen (a mais aguda) cobriria então uma oitava mais uma sexta maior. Por questões de comodidade de escrita, estes instrumentos propõem uma configuração dos teclados à imagem dos pianos partindo de fa3 e indo até o si4 (sendo o la3 o do diapasão). Claro, as lâminas tocadas não correspondem em nada a estas notas (MANOURY, 2012). ${ }^{3}$

O autor expõe ainda mais algumas evidências sobre as suas características de afinação:

\begin{abstract}
A natureza «individual» destes instrumentos que não fusionam entre si é muito prática no caso de polifonias e polirritmias. De fato, a percepção simultânea das camadas é reforçada pelo fato das linhas não se encontrarem em torno de linhas comuns mas, ao contrário, elas se afirmam em sua independência. A coerência deve então ser procurada em um outro domínio que aquele das alturas harmônicas, como é o caso na utilização dos instrumentos « clássicos », sendo que serão os tratamentos rítmicos e o jogo de figuras entre eles que assegurarão esta função (MANOURY, 2012, s.p.).
\end{abstract}

Quando Xenakis faz referência ao termo "SIX-XEN" na primeira página da grade de Pléïades (1978-79), ele está se referindo a uma unidade (um sixxen somente), afirmando o seguinte: "compreendendo dezenove alturas irregularmente distribuídas com distância de quartos de tons ou terços de tons ou seus múltiplos" (XENAKIS, 1978, p.1). No entanto, logo na sequência o compositor dá a entender que é com a totalidade que o efeito desejado será produzido "In addition the six copies of the instruments taken as a whole should never produce unisons." (XENAKIS, 1978, p.01 - Grifos nossos). Assim, Sixxen denomina, para ele um conjunto inseparável e interdependente composto por seis cópias não exatas sonoramente. Esta sutil diferença pode mudar conforme a perspectiva de análise das obras posteriores à Pléiades e mostrar a mudança do conceito original de Xenakis que ocorreu quando outros compositores passaram a escrever para sixxen solo ou para música de câmara utilizando somente um sexto (uma unidade), três sextos (três unidades) ou partes do conjunto original.

A concepção xenakiana demonstra assim um conceito de totalidade sonora, no sentido em que as características do que ele deseja são postas em evidência através do conjunto, em toda sua integralidade, ainda que hajam particularidades características, específicas e próprias a cada unidade. Ele não parece conceber o Sixxen como seis instrumentos colocados em ação conjuntamente mas, pelo contrário, como uma unidade total constituída por seis partes interdependentes, intrincadas e conexas, sendo cada uma tocada por um instrumentista. É a confluência das unidades que dá sentido ao todo, o tocar junto que confere o resultado desejado, a totalidade. 0 conjunto total será denominado aqui de Sixxen (com S maiúsculo), já as partes serão aqui chamadas de unidades ou sixxens (com s minúsculo) para se ter uma melhor atribuição de significado ao todo ou às partes especificamente.

\footnotetext{
${ }^{3}$ Destacamos que toda a discussão sobre escrita do instrumento será oportunamente apresentada em outro artigo subsequente a este.
} 
Com tal ideia, Xenakis contribuiu não só para a composição de nova obra mas para a própria definição e aumento da diversidade de estruturas e arranjos instrumentais possíveis e historicamente mapeados. Assim, compositores que passam a escrever para um novo meio de expressão musical são muitas vezes responsáveis por toda uma nova concepção instrumental, estilística e interpretativa. Em suas partituras marca-se e registra-se toda a gênese de um novo campo que se abre na arte musical. 0 que quer dizer que cada nova peça de um compositor experiente adiciona um importante, mas potencialmente instável, peso ao crescente e rápido senso da definição de percussão (SCHICK, 2006).

As definições e maneiras de descrever o Sixxen diversificaram-se nos meios de difusão e divulgação (impresso ou digital). Para STILLITANO \& SIMON (2013), o Sixxen será um instrumento "constituído por uma sucessão de lâminas metálicas afinadas em uma escala de quartos de tons e repartida entre seis teclados utilizados, cobrindo no total um âmbito de quase duas oitavas." Os autores afirmam que as baquetas utilizadas são "baquetas de vibrafone" ou de "gong/tam". Em nenhum momento Xenakis menciona que o material do Sixxen deveria resultar em lâminas (ainda que este tenha sido o resultado que ele aprovou para o Les Percussions de Strasbourg - Figura 1 e Figura 2).

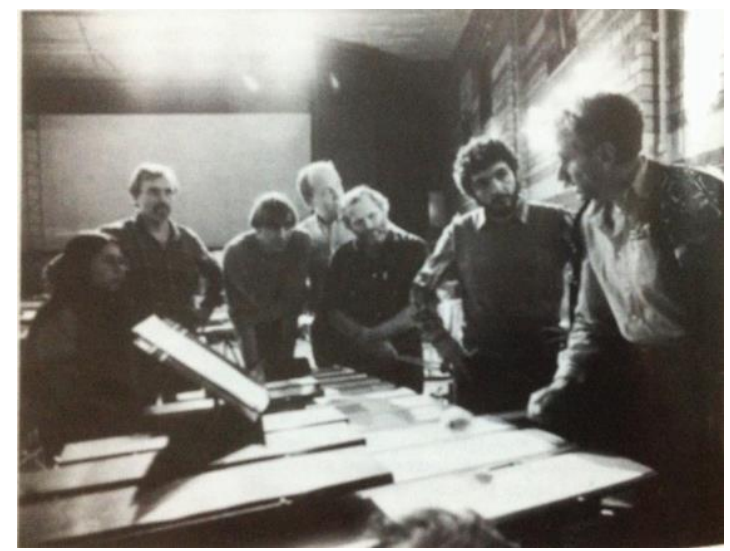

Figura 1: Xenakis (1ำ a direita) com os integrantes do Les Percussions de Strasbourg, experimentando um protótipo do Sixxen (XENAKIS, 1987, p.6).

Xenakis se limitou a definir a fonte sonora (metal) e a descrever certos aspectos de frequências. Tampouco restringiu quais baquetas deveriam ser utilizadas. Ainda assim, os autores acima concebem o total de teclas como uma gigantesca escala que é repartida em seis unidades ("seis teclados"), muito próximo das considerações de Xenakis.

Em um site de divulgação de um evento de percussão em Haia (Holanda) lê-se:

Os instrumentos consistem todos de dezenove placas de metal com o SIXXEN todo afinado com diferenças microtonais. A peça em si é baseada na mudança de tempi, com seis SIXXEN eventualmente se encaixando. Como eu entendo, os seis SIXXEN devem ser considerados como um instrumento (DAY OF PERCUSSION, 2012, s.p.). 


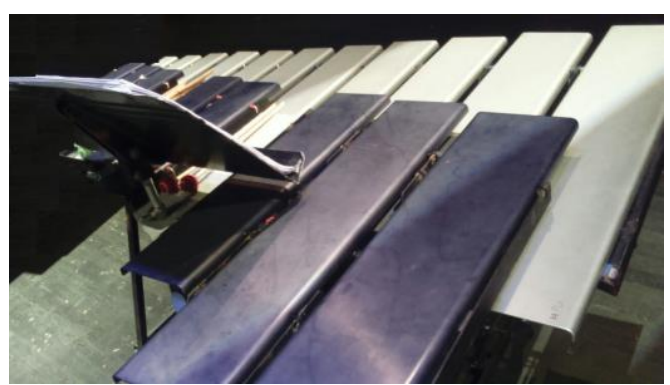

Figura 2: Detalhe da disposição das notas do Sixxen desenvolvido por Robert Hébrard para Iannis Xenakis e Les Percussions de Strasbourg 4 .

0 autor remete assim sua definição ao conceito xenakiano de totalidade, para ele os seis conjuntos de 19 teclas são assim considerados um instrumento somente. WANDERER afirma que: "[...] Xenakis inventou um tipo de vibrafone de metal, o Sixxen (Six para 6, xen para Xenakis) com som dificilmente suportável para orelhas sem proteção" (WANDERER, 2013, s.p.). Já LESNIE faz a seguinte afirmação: "O instrumento microtonal de metal com 19 notas, similar em aparência a uma marimba, foi projetado para ressaltar harmônicos discordantes entre as notas tocadas. 0 efeito é estridente e hipnotizante" (LESNIE, 2012, s.p.). Estes dois últimos conceitos aproximam o Sixxen de um teclado de percussão (tendo sido até mesmo chamado de vibrafone e comparado à marimba), mas Xenakis nunca afirmou que este se enquadraria em tal categoria, ele talvez não pensasse necessariamente que seria mais um tipo do grupo dos teclados, mesmo se o modelo original assim foi construído. 0 grupo Clocks in Motion o define da seguinte maneira:

Sixxen é constituído por seis teclados com 19 alturas
metálicas. Cada um dos seis teclados não é ajustado
exatamente na afinação do outro, mas pode estar
compreendido em até $3 / 4$ de tom dos demais. 0 resultado é
um tipo de escala confusa e não repetitiva. O sixxen é
extremamente sonoro e ressonante. Uma variedade de
baquetas e implementos podem soar bem com sixxen
(CLOCKS IN MOTION, s.d, s.p.).

O grupo também o concebe como um teclado de percussão (Figura 3) e deixam a total liberdade para o compositor no que diz respeito a baquetas utilizadas, quantidade de unidades utilizadas e relação com outros instrumentos para a composição de novas obras para o grupo.

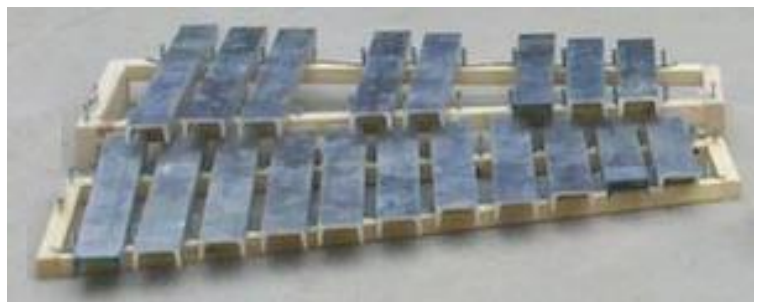

Figura 3: Uma unidade do Sixxen. Instrumento construído pelo grupo Clocks in Motion.

O compositor Philippe Manoury também o considera um teclado, até por isso insere dois movimentos com sexteto de Sixxen no Le livre des claviers. Ele afirma: "Além disso, a construção de novos instrumentos acústicos, como os sixxens, me permitiu enfrentar novos cenários neste

\footnotetext{
4 Foto: Sarah Brabo Durand.
} 
sentido: a noção de altura não é mais predominante mas torna-se mais complexa." (MANOURY, citado por LES PERCUSSIONS DE STRASBOURG, 2011).

Para os integrantes do grupo Third Coast o Sixxen é um instrumento não estandardizado mas configurado como marimba ou vibrafone em muitos aspectos, não sendo comercializado e, por isso, devendo ser construído pelo grupo interessado "partindo-se do zero":

Alguns destes instrumentos de teclado [usados em Pléïades] são os "estandarizados" (marimbas e um vibrafone), mas dois dos movimentos exigem um instrumento chamado "Sixxen". Sixxen foi inventado pelo compositor vanguardista grego e arquiteto Iannis Xenakis para seu sexteto de percussão monumental, Pleiades.

Embora o Sixxen seja configurado como uma marimba ou vibrafone em muitos aspectos, ele não é um instrumento padrão e não pode ser comprado em qualquer lugar nos Estados Unidos. Portanto, cabe a nós construir os instrumentos a partir do zero.

Assim como uma marimba ou vibrafone, eles parecem um pouco como um piano com "teclas brancas" e "teclas pretas" todas dispostas horizontalmente. A principal diferença é que cada Sixxen é propositadamente um pouco fora de ajuste com todos os demais Sixxen. Quando todos os seis instrumentos tocam juntos, esta ligeira diferença resulta em um turbilhão caleidoscópico de ressonâncias que competem entre si e que, quando experimentada ao vivo, cria um som que é tão carregado e vibrante que você sente quase como se pudesse chegar a pegá-lo e tocá-lo. (THIRD COAST, 2010, s.p.).

MEACHAM (2011) afirma:

O compositor inventou o "sixxen" para Pleiades, afirma Constable. Ou melhor, ele deu uma descrição bastante vaga de como ele achava que eles deveriam soar. Cada um tinha que ter 19 barras de bronze ou ligas de aço ou similar. Mas na partitura que eu tenho, Xenakis também deixou uma nota indicando que ele não estava feliz com qualquer um dos sixxens que tinha ouvido até agora [...]. Cada um dos sixxens em Pleiades tem que ter uma configuração ligeiramente diferente entre as 19 lâminas, em termos de seu comprimento e de sua ressonância (MEACHAM, 2011, s.p.).

ENGELMAN (2010) cita em uma nota de rodapé de seu site individual algumas afirmações que seriam do próprio Xenakis sobre o Sixxen:

SIXXEN é um instrumento especialmente construído nomeado a partir de Six (Strasbourg) e Xenakis. Mas o SIXXEN ainda não é inteiramente satisfatório. Seria desejável construir um novo. Esta é a sua descrição: cada um dos seis percussionistas utiliza 19 peças de metal (de latão, aço, etc.) com aproximadamente o mesmo timbre. É altamente desejável que o timbre seja realmente um timbre 
metálico muito interessante. Por interessante eu quero dizer surpreendente, estranho, cheio, ressonante e sem muita reverberação, de modo que os padrões rítmicos tocados possam ficar claros para o público. Estas 19 peças de metal devem ser ajustadas para produzir 19 alturas, mas não devem em absoluto formar uma escala de temperamento igual. 0 conjunto das 19 alturas é arbitrária e dependerá das peças disponíveis. No entanto, esta escala deve ser quase a mesma para todos os seis percussionistas e situadas no mesmo âmbito de alturas. Isto significa que para uma altura dada no âmbito das 19, e para qualquer um dos seis SIXXEN, os outros 5 correspondentes não devem formar uníssono. 0 desvio pode ser leve, mas ainda deve ser perceptível." (XENAKIS, citado por ENGELMAN, 2010, s.p.).

0 percussionista relembra ainda alguns fatos sobre a primeira vez que tocou a obra:

Meu primeiro encontro com Pléiades foi no início dos anos 1980 no Walter Hall da Universidade de Toronto. Xenakis foi o compositor convidado pelo flautista Bob Atkins para os New Music Concerts.

Acredito que nossa performance em Toronto foi a estréia canadense. A peça tem 43 minutos de duração e, além de tambores, marimbas e glockenspiels, Pléiades requer seis instrumentos que Xenakis reivindicada ter inventado, mas nunca construído. Ele chamou esses instrumentos "imaginados" Sixxen.

Se minha memória ainda serve, a descrição de Xenakis para o Sixxen era vaga. Cada Sixxen deveria consistir em 19 barras de metal ligeiramente fora de afinação dentro de uma tessitura similar, mas evitando uníssonos. 0 pai de um estudante de percussão da Universidade de Toronto trabalhou em uma fundição a cerca de 45 milhas ao norte de Toronto. Ele fez estes instrumentos gratuitamente e os entregou no Walter Hall.

Eles chegaram cobertos com óleo, sujeira e limalha de metal. Até o momento de descarregá-los e deixá-los prontos para serem tocados, as nossas mãos estavam imundas. Nós ensaiamos e lembro-me muito pouco sobre a peça, exceto que o som era brutalmente forte, muito difícil de tocar e suas páginas pretas com tantas notas. 0 falecido John Wyre teria dito: 'Isso não passa no teste de medidor de luz'. Wags sugeriu que a música tão forte de Xenakis era o resultado de sua surdez progressiva e isto parecia confirmado quando ele pedia repetidamente para que nós tocássemos mais forte. Xenakis chegou a trabalhar conosco nos últimos ensaios. Assim que ele ouviu a nossa versão do seu imaginário Sixxen, ele se opôs, afirmando que o som não era nada do que ele tinha em mente.

Lembro-me de ser atingido pelo fato de que ele foi indelicado. Ele não nos agradeceu ou reconheceu de qualquer forma a nossa tentativa de realizar suas instruções às vezes caprichosas, mas ainda assim sua nota de programa afirmou que o Sixxen era sua invenção e o coração de Pléiades. Muitos anos mais tarde eu aprendi que Xenakis se opusera ao Sixxen original que foi construído pelo Les 
Percussions de Strasbourg e, na verdade, a cada Sixxen construído durante a sua vida (ENGELMAN, 2010, s.p.).

O trecho acima mostra com clareza o que sintomaticamente era a relação de Xenakis com a construção de Sixxen: uma preocupação intensa, incansável e insistente com o timbre, uma busca constante e exaustiva por uma sonoridade somada a uma insatisfação perspicaz mas acima de tudo a uma necessidade de pesquisar e explorar os sons sempre, insistentemente e incessantemente.

\title{
3. Considerações históricas sobre o primeiro Sixxen construído: a relação entre Xenakis e Les Percussions de Strasbourg
}

\author{
"[Os percussionistas de Strasbourg] São fabricantes do som no seu estado concreto, \\ já eu os fabrico no estado abstrato..." \\ (XENAKIS, citado por BATIGNE, 1981, p.177).
}

Foram reunidos aqui alguns aspectos que podem trazer esclarecimentos sobre os primeiros momentos da criação original e do trabalho comum entre Iannis Xenakis e Les Percussions de Strasbourg quando da estreia da obra e escolha do protótipo que representaria a sonoridade desejada pelo compositor. Para Jean Batigne (um dos criadores do grupo francês), "Encontrar Xenakis é algo de muito importante. É ir em direção à história." (BATIGNE, 1981, p.175). Isso se torna menos metafórico e mais concreto com o primeiro trabalho em conjunto entre o seu grupo e o compositor. Quando Batigne solicitou que Xenakis compusesse a primeira peça para o grupo, este respondeu "Quando escreverei para vocês, esta será uma obra fundamental para a percussão" (XENAKIS, citado por BATIGNE, 1981, p.175) e assim surgiu Persephassa em 1969 estreada nas ruínas de Persépolis durante o primeiro Shiraz Festival.

\begin{abstract}
Situar Xenakis, como eu disse no começo, é encontrá-lo. E para encontrar alguém é preciso fazer a metade do caminho enquanto o outro percorre a outra metade. De 1969 a 1979 é isto o que ocorreu entre Xenakis e o grupo. [...] Quando da criação de Pléiades, eu pensei com meus amigos que o caminho do encontro tinha sido feito. Se a atitude de Xenakis no primeiro ensaio de Pléiades foi o mesmo que em Persépolis, nós ali conseguíamos compreender e acalmar a nossa própria inquietude. Na verdade, o que ocorre com este homem nestas circunstâncias, é que ele descobre de repente a concretude de sua obra. Como ele não consulta ninguém sobre sua música, ele vem escutar... o que ela dá. (BATIGNE, 1981, p.181-82)
\end{abstract}

Em troca de e-mails sobre a construção do primeiro Sixxen e sobre as particularidades que envolvem tal momento histórico, BERNARD (diretor artístico do Les Percussions durante anos) afirmou:

Aos meus conhecimentos sei da existência de 2 versões de sixxens na época: a primeira Kolberg, sem abafadores e com outra afinação, e a segunda que ficou sendo a aceita por Xenakis. A segunda versão é a atual, com o instrumento que permaneceu e que foi construído por Robert Hébrard que é genial para a construção de instrumentos derivados de 
madeira, canas, novas criações.... 0 problema desse sixxen é que ele não respeita a afinação imaginada por Xenakis. Por outro lado eu sei que Iannis gostava muito deste instrumento porque ele era rico em harmônicos, parciais... Mas, finalmente, como ele era um compositor sempre ligado à pesquisa sonora, à procura dos sons continuamente, tentamos buscar um novo sixxen com a firma Yamaha, também era para comercializá-lo. Infelizmente, apesar de várias viagens de Iannis para o Japão, na apresentação do novo sixxen construído pela Yamaha, Xenakis ainda quis mudar e o projeto com a Yamaha foi abandonado.

Finalmente, os percussionistas [de Strasbourg] tocam ainda com os sixxens de Hébrard. Philippe Manoury também escreveu algumas peças muito interessantes com os nossos sixxens que infelizmente são únicos. 0 grupo Kroumata queria comprar os mesmos sixxens com Hébrard mas ele não conseguiu refazê-los exatamente iguais! (BERNARD, 2015, s.p.).

0 protótipo de Robert Hébrard é então o modelo que passa a fazer parte de todas as apresentações de Pléïades do grupo. 0 perfil das lâminas ${ }^{5}$ deste é em U invertido com arestas abauladas e as laterais proporcionalmente 1/15 de superfície da face de ataque. As 19 lâminas são dispostas horizontalmente indo das mais graves para as mais agudas da esquerda para a direita. Há diferença de altura entre o teclado mais próximo ao executante e o mais afastado (como em uma marimba com as teclas F\#, G\#, A\#, C\# e D\#), há ainda a diferença de cor entre os dois tipos de jogos de lâmina (como em um piano com as teclas brancas e teclas pretas). Os tamanhos das teclas se configuram entre os maiores até então encontrados em todos os Sixxens revisados até a redação do artigo. 0 corpo de sustentação é caracterizado por um quadro em metal relativamente fino e com rodas, se apoiando assim ao solo por uma base estável de aço em contato por quatro pontos de apoio. Nos espaços entre as teclas pretas (as lâminas representadas na partitura por $\mathrm{F} \#, \mathrm{G \#}, \mathrm{A \#}, \mathrm{C \#}$ e $\mathrm{D \#}$ ), existem mesinhas para se colocar e se deixar as baquetas ou instrumentos pequenos. Há um sistema de pedal presente mas, diferente do sistema de um vibrafone comum, este sistema mantém as lâminas livres continuamente e o acionamento do pedal pressionando-o faz com que os abafadores encostem nas teclas. Ele é assim um sistema de abafamento com ação inversa ao do vibrafone, ele abafa os corpos vibratórios quando acionado e deixa os corpos livres quando não pressionado. 0 sistema de abafamento está presente no protótipo de Hébrard ainda que Xenakis não tenha exigido tal mecanismo e mesmo que na partitura não haja nenhuma indicação de pedal. Este instrumento acima descrito será chamado de protótipo-tipo, assim denominado para diferenciá-lo das demais unidades prototípicas que foram criadas tanto para os percussionistas de Strasbourg quanto por outros grupos e instituições.

MANOURY (2012) realizou uma gravação e análise pormenorizada dos sons do Sixxen de Hébrard e afirma:

Dentre os instrumentos mais criativos que foram construídos no fim do Séc. XX deve-se mencionar o Sixxen.

\footnotetext{
${ }^{5}$ Que tem como metal empregado o Dural (também conhecido como duralumínio e duralium), essencialmente constituído por $95 \%$ alumínio, $4 \%$ cobre, $0.5 \%$ magnésio e $0.5 \%$ manganês e possíveis traços de outros elementos metálicos.
} 
Sua criação é atribuída ao luthier Robert Hébrard que o concebeu a pedido de Iannis Xenakis. O fenômeno [de criação deste instrumento] é ainda mais interessante quando se constata que a pesquisa no campo acústico foi, durante anos, totalmente suplantada pela pesquisa em eletrônica. Existem evidentemente numerosos casos nos quais novos instrumentos acústicos foram inventados (sendo o exemplo mais celebre o do compositor estadunidense Harry Partch) mas, geralmente, os performers destes instrumentos se limitam aos inventores dos mesmos. Diversas gerações de sixxens foram criadas antes da que nós conhecemos hoje. Não há contudo estandardização nestes instrumentos que soam assaz diferentes segundo sua construção. Sabemos, por testemunhos, que Xenakis queria que estes instrumentos fossem afinados em uma escala de quarto de tom e que ele não tinha deixado ideias muito precisas sobre a maneira que ele queria que estes soassem. Ele desejava simplesmente que eles não soassem de "maneira clássica », o que está longe de ser uma definição precisa. Sabemos que ele tinha imaginado que as teclas fossem de porcelana muito dura e não de metal. (MANOURY, 2012, s.p.).

As considerações de Manoury parecem ser importantes para se compreender o 'fenômeno' Sixxen. A afirmação sobre o fato de Xenakis imaginar a matéria-prima ser porcelana parece suscitar novas interrogações sobre essa constante busca sonora do compositor, sobre o seu eterno escutar, experimentar e revisar ideias e possibilidades. Se estas considerações mudaram ao longo do processo de constituição do protótipo-tipo encontram-se poucas discussões sobre esta declaração de Manoury, sendo ele o único a fazer tal afirmação. Sobre o protótipo-tipo, BERNARD afirma:

Este instrumento (em todo caso, a versão que nós temos) é absolutamente fantástico, porque ele é de uma riqueza absoluta: podemos tocar pppp ou ffff, ele não satura nunca e, para mim, é importante ressaltar isso pois, às vezes, se confunde isso com uma certa brutalidade, sendo que na verdade se trata de uma matéria e de um timbre excepcionais. (BERNARD, citado por BARTHEL-CALVET, 2011, p.22).

\section{MANOURY (2012) nos traz alguns mais detalhes sobre tais características:}

Os sixxens [de Strasbourg] possuem uma característica muito particular. Como em todo instrumento percutido, as variações dinâmicas fazem ressoar densidades espectrais diferentes : um som de fraca intensidade terá poucos parciais enquanto um som de forte intensidade colocará em relevo um grande número deles. No caso dos sons com forte 'harmonicidade' (como os de piano ou de marimba por exemplo) a sensação da altura não variará com o nível de dinâmica visto que a natureza harmônica permanecerá o elemento determinante para a percepção da altura fundamental (princípio da fusão espectral). No caso dos sixxens, pela sua forte 'inarmonicidade', as variações de 


\begin{abstract}
intensidade farão aparecer parciais que não fusionarão com nenhuma altura fundamental qualquer mas, ao contrário, produzirão « cores » suplementares e estranhas ao espectro de uma mesma nota tocada em uma dinâmica fraca. A sensação da altura irá variar então segundo os níveis de ataque dos sons. (MANOURY, 2012, s.p.).
\end{abstract}

A partitura inicial de Métaux e os excertos com Sixxen de Mélanges eram constituídas por 6 partes individuais com inúmeras linhas cada. A notação original imaginada para Sixxen representaria uma linha ou espaço para cada altura, para cada frequência, sendo dispostas simetricamente do grave ao agudo de baixo para cima e em dois tipos de claves. Eram usadas as claves de sol e de fá, mas obviamente não existia relação direta com as frequências dispostas nestas claves e nem relação da visualidade da partitura com a disposição das teclas no corpo do instrumento. Assim, as 19 alturas gravadas na partitura e repartidas entre linhas e espaços constantes (dispostas basicamente em duas claves e com quase 4 oitavas para serem lidas) eram dificilmente relacionadas às teclas que deviam ser tocadas com a disposição das lâminas de Sixxen (que representava basicamente a disposição de uma só clave e com 1 oitava e meia de extensão). É em função destas e de inúmeras outras questões que os percussionistas de Strasbourg resolveram mudar a forma de notação para o instrumento. Segundo BERNARD:

\footnotetext{
Na verdade eu acho que foram os próprios percussionistas que fizeram primeiro uma transcrição para a notação tradicional, depois esta foi assim editada. A clave de sol é inútil: era apenas para reescrever a partitura original que tinha 19 linhas por sistema ao invés de uma pauta normal de 5 linhas. Claro, o que lemos não corresponde à altura exata dos sons (BERNARD, 2015, s.p.)
}

Percebe-se então que a partitura original tinha um grande desafio a ser vencido, a partitura era dividida entre clave de fá e clave de sol com um âmbito bastante abrangente, porém o Sixxen tinha suas teclas dispostas de maneira mais restrita com uma geografia específica para uma oitava e meia. Talvez este ponto seja importante de ser enfatizado pois inicialmente Xenakis talvez não estivesse pensando em um teclado de percussão, ele parecia mais distante de pensar o Sixxen como um teclado de percussão. A notação de Métaux talvez estivesse originalmente muito mais próxima de uma notação de percussão múltipla (como por exemplo na partitura de Thirteen drums - ISHII, 1985 - composta para 13 tambores), e o tipo de resultado gráfico (ainda que três vezes maior) estaria mais próximo das partes individuais de Peaux do que de Claviers, o que foi alterado radicalmente com a atitude dos intérpretes. Com a aplicação da clave de sol (ainda que esta seja completamente relativizada pela falta de correlação real com as frequências específicas, como bem relembra Jean-Paul Bernard), o Sixxen passou a ter uma apropriação visual através da partitura correlata à leitura dos teclados de percussão. Um dos motivos para a mudança da partitura era a possibilidade de se ler com mais agilidade as notas em seus mais sutis interstícios, o que foi corroborado ainda mais pela disposição das lâminas feita como em um teclado de percussão. Este foi um divisor de águas no que tange à morfologia e disposição das teclas do instrumento e, como será visto mais adiante, nenhum modelo básico de construção até o momento realizado fugiu desta disposição e desta forma de organizar as suas frequências. Ainda sobre as relações de Xenakis com o Les Percussions de Strasbourg, BATIGNE (1981) diz que: 


\begin{abstract}
Ele mesmo é de fato mais inquieto que o poderia ser a totalidade de seus intérpretes; ele sabe escutar e é por isso que ele não fala e não responde às interrogações imediatas do intérprete, pois no silêncio ele procede à análise, até mesmo à autocrítica do que ele acaba de perceber. (BATIGNE, 1981, p.183).
\end{abstract}

Esta inquietação de Xenakis para com sua obra foi também percebida por Jean-Paul Bernard especificamente para com Pléïades e com o Sixxen: "Eu sempre tive a impressão que, mesmo sendo uma obra tocada durante muitos anos, cada vez Xenakis a redescobria em parte por causa deste instrumento prototípico" (BERNARD, citado por BARTHEL - CALVET, 2011, p.22).

Jean-Paul Bernard afirma que o primeiro contato que teve com Iannis Xenakis foi relacionado com a peça Pléiades e, para ele, o Sixxen "É quase o último elemento criado pela luteria instrumental acústica no século precedente (...) e existem só protótipos.” (BERNARD, citado por BARTHEL-CALVET, 2011, p.22).

Esta afirmação demonstra como um instrumento como esse, com amplo interesse de construção por grupos os mais variados e de análise e trabalho por compositores diversos, tem continuado alvo de constantes pesquisas sobre sua sonoridade e modos de fabricação. Xenakis, ao não deixar um protótipo modelo aceito ou um modelo que pudesse ser comercializado e que fosse estandardizado ou patenteado, acabou tornando eterna a busca por essa sonoridade para Pléïades. Ele, com sua incessante busca sonora e constante insatisfação por um ideal de timbre e instrumento, legou aos novos construtores e intérpretes mais possibilidades do que restrições, mais dúvidas do que afirmações, mais questionamentos do que respostas, fazendo com que sua pesquisa sonora continuasse viva e ativa. É assim perceptível como a busca perspicaz do compositor em vida permanece presente, faz parte da realidade atual e parece poder permanecer ainda em um futuro onde mais modelos e protótipos surgirão. Essa busca obstinada, insistente e 'insatisfeita' de Xenakis acaba se refletindo na diversidade de protótipos e modelos que serão agora apresentados.

\section{Os Sixxens construídos pelo mundo e considerações estruturais}

Esta pesquisa considerou fontes ${ }^{6}$ de informação as mais diversificadas (bibliográficas, periódicos, sítios da web, registros audiovisuais, programas de concerto, notas críticas e revisões de gravações além de contatos pessoais com profissionais). Assim, o presente incluiu o levantamento de dados a respeito do quantitativo de grupos que construíram Sixxen pelo mundo. Tem-se como resultado atual um total de 60 grupos que o construíram, de maneiras variadas e com características as mais diversas. Os grupos até o presente momento catalogados e os instrumentos repertoriados, estão situados em 21 países e são mostrados de modo sintético (Figura 4 e Figura 5). Alguns instrumentos podem estar repetidos pois podem ser um mesmo instrumento utilizado por diferentes grupos. Assim, o protótipo do Queens College e do grupo Talujon pode ser o mesmo, o protótipo utilizado para o concerto TROMP Laureates pode ser o mesmo de alguma outra instituição ou pode ter sido alugado.

\footnotetext{
60 acesso às informações sobre modelos e protótipos e todo o reservatório de referências da revisão documental, estão disponibilizados e podem ser consultados no sítio da web https://www.ronangil.com/sixxenproject-inicial.
} 
Percebemos com esse quantitativo que, em pouco mais de trinta anos, o Sixxen é um instrumento que vem se consolidando em diversos países, mas com maior predominância nos EUA, seguido por França e Alemanha. Observa-se ainda que a maioria dos Sixxens construídos tem lâminas feitas a partir de alumínio e há uma certa preferência pelo perfil em U invertido. Em meio ao quantitativo de instrumentos construídos, um modelo se diferencia bastante, tendo sido construído como um sixxen mecanizado. 0 protótipo é uma realização de Thomas Sturm de outubro de 2016 e é parte de suas pesquisas com instrumentos mecanizados.

\begin{tabular}{|c|c|c|c|c|c|c|c|c|c|}
\hline \multirow{3}{*}{ Grupo /Artista } & \multirow{3}{*}{ País } & \multirow{3}{*}{ Material } & \multicolumn{5}{|c|}{ Perfil das Notas } & \multirow{3}{*}{ Pedal } & \multirow{3}{*}{ Tubos } \\
\hline & & & \multicolumn{2}{|c|}{ U invertido } & \multirow{2}{*}{$\begin{array}{c}\text { Tubo } \\
\text { quadrado }\end{array}$} & \multirow[b]{2}{*}{ Lâmina } & \multirow{2}{*}{$\begin{array}{c}\mathrm{L} \\
\text { invertido }\end{array}$} & & \\
\hline & & & $\begin{array}{l}\text { Lados } \\
\text { iguais }\end{array}$ & $\begin{array}{c}\text { Lados } \\
\text { desiguais }\end{array}$ & & & & & \\
\hline $\begin{array}{l}\text { Hoschule für Musik und } \\
\text { Darstellende Kunst } \\
\text { Frankfurt }\end{array}$ & Alemanha & Alumínio & - & $\mathrm{X}$ & - & - & - & - & - \\
\hline $\begin{array}{l}\text { Synergy Percussion } \\
\text { Group }\end{array}$ & Austrália & $\begin{array}{l}\text { Alumínio e } 2 \text { tipos } \\
\text { de liga de ferro }\end{array}$ & - & $\mathrm{X}$ & - & $\mathrm{x}$ & - & - & - \\
\hline $\begin{array}{l}\text { Martin Grubinger / } \\
\text { Percussive Planet }\end{array}$ & Áustria & Alumínio & - & $\mathrm{X}$ & - & - & - & - & - \\
\hline $\begin{array}{l}\text { Roga Percussion } \\
\text { Solution }\end{array}$ & Bélgica & Alumínio & - & $\mathrm{X}$ & - & - & - & - & - \\
\hline Impact(o) & Brasil & Aço Inoxidável & - & - & - & - & $\bar{X}$ & $\bar{X}$ & - \\
\hline Sixtrum & Canadá & Alumínio & - & $\mathrm{X}$ & - & - & - & - & - \\
\hline Tom Hunter & Escócia & Alumínio & $\mathrm{X}$ & - & - & - & - & - & - \\
\hline $\begin{array}{l}\text { Gert Mortensen } \\
\text { /Percurama }\end{array}$ & Dinamarca & Inox & - & - & $\mathrm{X}$ & - & - & - & - \\
\hline Chamber Cartel & EUA & Alumínio & - & $\mathrm{X}$ & - & - & - & - & - \\
\hline Clocks in motion & EUA & Alumínio & - & $\mathrm{X}$ & - & - & - & - & - \\
\hline Joseph Murfin & EUA & Alumínio & - & $\mathrm{X}$ & - & - & - & - & - \\
\hline Juilliard School of Music & EUA & Alumínio & - & $\bar{X}$ & - & - & - & - & - \\
\hline Queens College (CUNY) & EUA & Alumínio & - & $\bar{X}$ & - & - & - & - & - \\
\hline $\begin{array}{l}\text { SO Percussion / } \\
\text { Meehan-Perkins Duo }\end{array}$ & EUA & Alumínio & - & - & $\mathrm{x}$ & - & - & - & - \\
\hline Stony Brook University & $\overline{E U A}$ & Alumínio & - & $\bar{X}$ & - & - & - & - & - \\
\hline Talujon & EUA & Alumínio & - & $\mathrm{X}$ & - & - & - & - & - \\
\hline Third Coast Percussion & EUA & Alumínio & - & $\mathrm{X}$ & - & - & - & $\bar{X}$ & - \\
\hline $\begin{array}{l}\text { University of Tennessee } \\
\text { Knoxville }\end{array}$ & EUA & Alumínio & - & $\mathrm{x}$ & - & - & - & - & - \\
\hline $\begin{array}{l}\text { UC San Diego - Red Fish } \\
\text { Blue Fish }\end{array}$ & EUA & Alumínio & - & $\mathrm{x}$ & - & - & - & - & - \\
\hline UT Austin - UTPG & $\overline{\text { EUA }}$ & Ferro & - & $\bar{X}$ & - & - & - & - & - \\
\hline $\begin{array}{l}\text { Yale University } \\
\text { Percussion Group }\end{array}$ & EUA & Alumínio & - & $\mathrm{x}$ & - & - & - & - & - \\
\hline Bergerault* & França & $?$ & - & $\mathrm{X}$ & - & - & - & $\bar{X}$ & $\bar{X}$ \\
\hline $\begin{array}{l}\text { Conservatoire de Saint } \\
\text { Cloud - Eve Payeur }\end{array}$ & França & Alumínio & - & $\mathrm{X}$ & - & - & - & $\mathrm{x}$ & $\mathrm{x}$ \\
\hline $\begin{array}{l}\text { Les Percussions de } \\
\text { Strasbourg }\end{array}$ & França & Dural & - & $\mathrm{X}$ & - & - & - & $\mathrm{X}$ & - \\
\hline Slagwerk Den Haag & Holanda & Alumínio & - & - & - & $\mathrm{X}$ & - & - & $\bar{X}$ \\
\hline 4-Mallety & Inglaterra & Alumínio & - & $\mathrm{X}$ & - & - & - & - & \\
\hline Bell Percussion* & Inglaterra & Alumínio & - & $\mathrm{X}$ & - & - & - & - & - \\
\hline Brake Drum Percussion & Itália & $\begin{array}{c}\text { 1 Sixxen Bronze } \\
\text { 1 Sixxen Alumínio }\end{array}$ & - & - & $\begin{array}{c}\mathrm{X} \\
\text { Alumínio }\end{array}$ & $\begin{array}{c}\mathrm{X} \\
\text { Bronze }\end{array}$ & - & - & - \\
\hline Kuniko Kato & $\begin{array}{l}\text { Japão/ } \\
\text { EUA }\end{array}$ & Aço Inoxidável & - & - & $\mathrm{x}$ & - & - & - & - \\
\hline Academia Cervantina & México & Alumínio & - & - & $\mathrm{X}$ & - & - & - & - \\
\hline Tambuco & México & Alumínio & $\bar{X}$ & - & - & - & - & - & - \\
\hline Drumming & Portugal & Alumínio & $\mathrm{X}$ & - & - & - & - & - & - \\
\hline Usine Sonore & Suíça & Alumínio & - & $\bar{X}$ & - & - & - & - & - \\
\hline
\end{tabular}

* Modelo Industrializado 
Figura 4: Tabela com listagem, por ordem alfabética de origem, de Sixxens construídos em diferentes países, com respectivas características de construção (material constitutivo, perfil das notas, pedal, tubos).

\begin{tabular}{|l|l|}
\hline \multicolumn{1}{|c|}{ Sixxen construído por } & \multicolumn{1}{c|}{ País } \\
\hline Peter Sadlo & Alemanha \\
\hline Kolberg* (modelo industrializado) & Alemanha \\
\hline Hoschule für Musik Freiburg & Alemanha \\
\hline Percussion Art Quartet & Alemanha \\
\hline Ensamble Tambor Fantasma & Argentina \\
\hline Nova Ensemble & Austrália \\
\hline University of Western Australia & Austrália \\
\hline Percussionisten Conservatorium Brussel & Bélgica \\
\hline Nexus & Canadá \\
\hline Neopercussión & Espanha \\
\hline Georgia State University (GPC) & EUA \\
\hline Oberlin College & EUA \\
\hline Rowan University & EUA \\
\hline Baylor PG/Line upon Line/Meehan-Perkins Duo & EUA \\
\hline Madison Percussion Group & EUA \\
\hline Crossing 32nd Street & EUA \\
\hline Eastman School of Music & EUA \\
\hline UNCG Percussion Group & EUA \\
\hline Simone Mancuso & Itália \\
\hline Les Pléïades - Sylvio Gualda & França \\
\hline Percussions des Jardins Musicaux & França \\
\hline Typana Percussion Ensemble & Grécia \\
\hline Makoto Aruga Percussion Ensemble & Japão \\
\hline Kroumata Percussion Group & Suécia \\
\hline Centre International de Percussion de Genève & Suíça \\
\hline Collectif Eklekto & Suíça \\
\hline Ensemble Arc-Em-Ciel & Suíça \\
\hline & \\
\hline
\end{tabular}

Figura 5: Tabela com listagem, por ordem alfabética de origem, de grupos ou indivíduos que possuem Sixxen, mas sem as características que o constitui.

Alguns protótipos vão na contramão da tendência mais observada (uso do material alumínio e perfil U invertido), como é o caso do Sixxen desenvolvido pelo Núcleo de Excelência para o Ensino, Pesquisa e Performance em Percussão - N $\equiv \mathrm{P}^{3}$, para o grupo de percussão Impact(o). 0 protótipo foi construído via projeto de pesquisa com fomento do CNPq/SEC/MinC e tratou-se do primeiro desse gênero desenvolvido no Brasil. 0 modelo desenvolvido representou uma escolha distinta das anteriores pelo uso de um perfil em "L" invertido (ou cantoneira) de aço inoxidável (Figura 6 e Figura 7). 


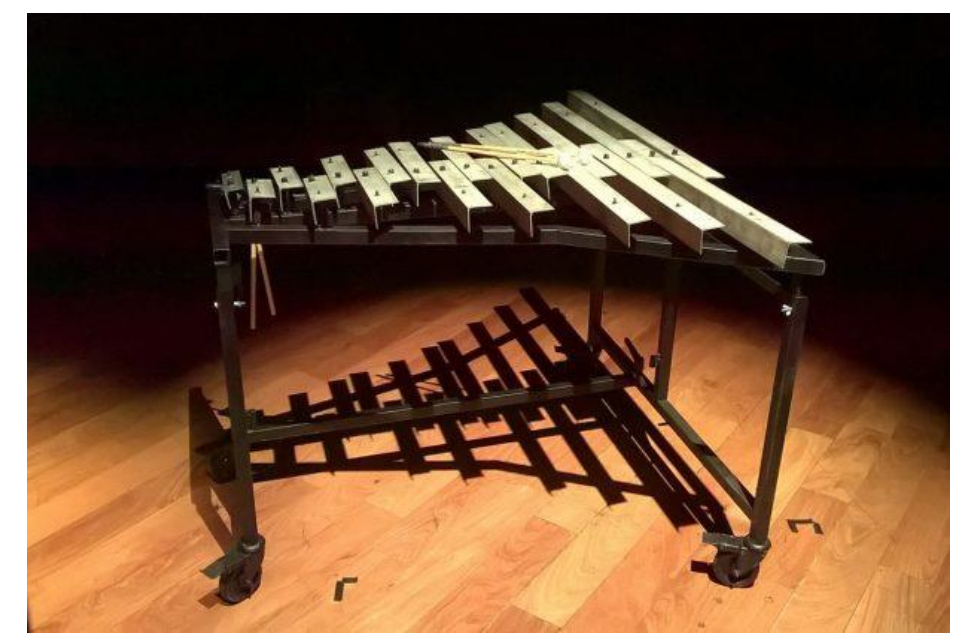

Figura 6: Uma unidade do protótipo desenvolvido pelo Núcleo de Excelência para o Ensino, Pesquisa e Performance em Percussão - N $\equiv \mathrm{P}^{3}$ (Goiânia, GO, Brasil).

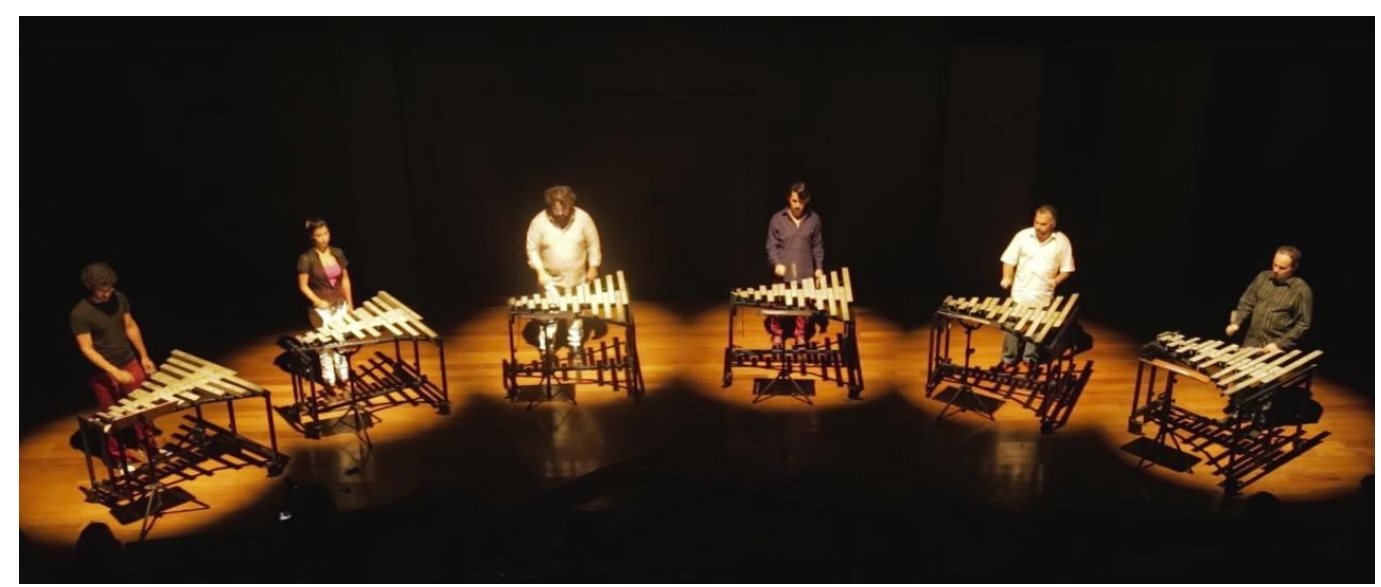

Figura 7: Panorama do palco montado para concerto com o Sixxen completo, desenvolvido pelo Núcleo de Excelência para o Ensino, Pesquisa e Performance em Percussão - N $\equiv \mathrm{P}^{3}$ (Goiânia, GO, Brasil). ${ }^{7}$

O grupo que decide tocar a obra de Xenakis, na maioria dos casos, participa do processo de construção do instrumento. Eles acabam coletando algumas fotos no processo de construção tornando acessível esse material, fazendo com que se possa compreender melhor as escolhas estruturais por eles realizadas. Nessas fotos se percebe também a diferença no corpo do instrumento, no modo de suspensão dos metais (se por cordas ou se diretamente pousado no corpo do instrumento, entre outros).

Sobre questões comerciais do instrumento, existem quatro empresas que se interessaram em uma produção inicialmente (Kolberg, Yamaha, Bergerault e Bell Percussion), sendo que somente duas oferecem sua aquisição através de encomenda atualmente.

\section{Considerações Finais}

O presente projeto escrutinou uma ampla quantidade de informações sobre Sixxen pelo mundo. A quantidade de protótipos e construtores pelo mundo mostra a importância da obra, de seu

\footnotetext{
${ }^{7}$ Concerto realizado pelo Impact(o), no Centro Cultural da UFG (CCUFG), Goiânia (GO), em 10 de Novembro de 2015, às 20h 30min. Percussionistas: Leonardo Labrada, Catarina Percínio, Fabio Oliveira, Leonardo Caire, Fernando Chaib e Ronan Gil.
} 
criador e do instrumento na história da percussão e certamente para o histórico de criação, desenvolvimento e inovação de novos instrumentos e conceitos instrumentais.

Os dados aqui revelados mostram parte da história sobre o instrumento Sixxen, instrumento este que tem uma história relativamente recente (40 anos em breve) mas que não pode mergulhar no esquecimento por uma não formalização de seus aspectos os mais básicos. É notório que ainda se pode contactar atualmente músicos que trabalharam diretamente com Xenakis e suas experiências pessoais e profissionais com o compositor não podem ser perdidas pela falta de registo.

Até o presente todas as configurações de Sixxen podem enquadrá-lo de certa maneira como um teclado de percussão, porém este fato não é algo determinado a priori pelo compositor, quiçá poderá ser colocada em prática uma proposição completamente diferente, mais próxima a uma múltipla percussão ou conjunto instrumental organizado de outro modo como placas metálicas suspensas em posição vertical ou tubos metálicos em disposição diagonal, enfim existem ainda múltiplas possibilidades sonoras não experimentadas.

Mais trabalhos poderão registrar aspectos relacionados ao Sixxen, ao seu repertório e aos agentes que atuaram ou atuam neste universo. Outros aspectos poderão ampliar ainda mais as considerações sobre esta criação xenakiana. Certamente outros protótipos já existente mas não mencionados aqui surgirão, bem como mais modelos e abordagens construtivas para a resolução de seus problemas práticos e performativos.

Xenakis representa ainda a personificação dos dilemas, contradições e impasses do séc. XX e transição para o XXI, pois como bem o descreve MÂCHE (1981, p.164.): “Ele é fascinado ao mesmo tempo pelo mais longínquo passado da humanidade e do universo, bem como pela formidável crise terrestre que significa a aproximação do séc. XXI." Ele representa assim a personificação das multi-dimensões possíveis na pesquisa em música e no diálogo entre música e ciência. É certo que ainda não se exauriu a imensa fonte e arcabouço de conhecimentos, saberes e possibilidades que representa a obra de Xenakis. Ele permanecerá como ponto central e pedra fundamental de dúvidas, anseios, questionamentos, soluções e proposições da comunidade percussiva por tempo infindável. A obra de Xenakis é representativa na história da percussão e é marcada por uma força telúrica ímpar e também característica da percussão no séc. XX.

Foi criado o site Sixxen Project para maiores informações sobre o instrumento, sendo ele concebido para que se possa reunir as informações sobre Sixxen e complementar o arquivamento de informações sobre o instrumento, disponibilizando ainda links e outras informações aos interessados. 0 site pode ser visualizado através do endereço https://www.ronangil.com/sixxenproject-inicial ou pode-se acessá-lo através do site www.ronangil.com e clicando-se no link Sixxen Project. Assim, procura-se constituir uma base de dados e de referências que possa auxiliar percussionistas, pesquisadores e interessados a acessar informações e que possa servir ainda de repositório de informações para quem quiser ter acesso às suas informações e disponibilizar os detalhes de seu próprio instrumento. Assim, procura-se contemplar futuras interconexões possíveis com outros percussionistas, instituições e grupos de pesquisa e divulga-se a colaboração e fomento institucional de todos os órgãos de financiamento envolvidos. 


\section{Referências de texto}

1. BARTHEL-CALVET, Anne-Sylvie (Coord.). Oser Xenakis. Dix ans après la disparition de Iannis Xenakis, le monde musical est loin d'avoir fini d'évaluer l'importance de l'héritage dont il est dépositaire. Paris: Ed. DurandSalabert-Eschig, 2011.31p.

2. BATIGNE, Jean. Sur Persephassa et Pléiades. In: GERHARDS, Hugues (Org.). Regards sur Iannis Xenakis. Paris: Ed. Stock Musique, 1981. p.175-83.

3. BERNARD, Jean-Paul. Sixxen et Xenakis. [mensagem pessoal]. Mensagem recebida por ronangil@gmail.com em 30/03/2015.

4. CLOCKS IN MOTION. Memo to composers. s.d. Disponível em:

<http://clocksinmotionpercussion.com/about/memo-to-composers/>. Acesso em: 20/03/2015.

5. DAY OF PERCUSSION. Heavy slamming at the day of percussion. 2012. Disponível em:

<http://home.kpn.nl/h.p.eeuwes/a/2012/dayofpercussion2012.htm>. Acesso em: 20/05/2015.

6. ENGELMAN, Robin. So Percussion + Meehan / Perkins Duo. 2010. Disponível em:

<http://robinengelman.com/2010/12/02/so-2/>. Acesso em: 21/04/2015.

7. HARLEY, James. Xenakis: His Life in Music. Nova York: Ed. Routledge, 2004. 272p.

8. ISHII, Maki. Thirteen Drums. Celle: Editions Moeck. 1985.

9. LACROIX, Marie-Hortense. Pléïades de Yannis Xenakis. Musique et analyse. Paris: Ed. TUM - Michel de Maule, 2001. 106p.

10. LESNIE, Melissa. The 12 wackiest musical instruments. 2012. Disponível em: <http://www.limelightmagazine.com.au/Article/288901\%2Cthe-12-wackiest-musicalinstruments.aspx $>$. Acesso em: 10/08/2015.

11. LES PERCUSSIONS DE STRASBOURG. Notes de Programme. 2011. Disponível em:

<https://www.mcgill.ca/music/files/music/28.feb_percussions.de.strasbourg.prog2.pdf>. Acesso em: $07 / 05 / 2015$.

12. LES PERCUSSIONS DE STRASBOURG. Pléiades. s.d. Disponível em:

<http:// www.percussionsdestrasbourg.com/repertoire/pleiades-conducteur-5/>. Acesso em: 05/05/2015.

13. MÂCHE, François-Bernard. Iannis Xenakis. Introduction aux oeuvres. In: GERHARDS, Hugues (Org.). Regards sur Iannis Xenakis. Paris: Ed. Stock Musique, 1981. p.153-66.

14. MANOURY, Philippe. Traité d'inharmonie. 2012. Disponível em:

<http:// www.philippemanoury.com/?p=4965>. Acesso em: 19/07/2015.

15. MARANDOLA, Fabrice. Of Paradigms and Drums: Analysing and Performing Peaux from Pléiades. In: KANACH, Sharon (Org.). Xenakis Matters. Nova York: Pendragon Press, 2012. p.185-204.

16. MEACHAM, Steve. Percussionists try their hand at heavy metal. 2011. Disponível em: <http://www.smh.com.au/entertainment/music/percussionists-try-their-hand-atheavy-metal-201106061fp4t.html>. Acesso em: 21/06/2015.

17. NEWS. New percussion ensemble work premiered. Percussionist, Vol.1, No. 3, p.14-16, 1982.

18. REED, Brett. Building a Set of Sixxen. Percussive notes, Vol. 41, No. 3, p.48-50, 2003. 
MORAIS, Ronan Gil de; CHAIB, Fernando Martins de Castro; OLIVEIRA, Fabio Fonseca de. (2017) Considerações históricas, estruturais e características sobre o instrumento Sixxen, de Iannis Xenakis. Per Musi, Belo Horizonte: UFMG. p.1-21.

19. SCHICK, Steven. The Percussionist's Art: Same Bed, Different Dreams. Nova York: University of Rochester Press, 2006. 272p.

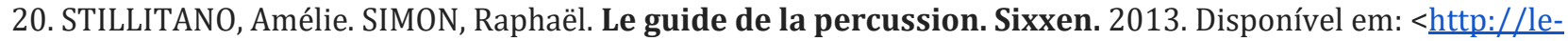
guide-de-la-percussion.com/instruments/categorie/1414- metaux/instrument/1423-sixxen>. Acesso em: $21 / 06 / 2015$.

21. THIRD COAST. What the heck is a Sixxen? 2010. Disponível em: <http:// thirdcoastpercussion.tumblr.com/post/859065480/what-the-heck-is-a-sixxen>. Acesso em: $05 / 05 / 2015$.

22. WANDERER. LUCERNE FESTIVAL 2013: LATE NIGHT CONCERT le 17 août 2013, MARTIN GRUBINGER et THE PERCUSSIVE PLANET ENSEMBLE (Percussions) (XENAKIS-BARTÓK) avec FERHAN et FERZAN ÖNDER (Piano). 2013. Disponível em: <http://wanderer.blog.lemonde.fr/tag/yannis-xenakis/>. Acesso em: $21 / 05 / 2015$

\section{Referências de partitura}

1. XENAKIS, Iannis. Pléïades. Paris: Ed. Salabert, 1978.

2. Kéleütha. Ecrits. Paris: Ed. L’Arche, 1994. 143p.

\section{Referência de gravação}

1. XENAKIS, Iannis PLÉİADES - Les Percussions de Strasbourg (1987). In: Musique Française D’aujourd'hui. Arles: Harmonie Mundi. Direção de François Dhalmann. Com Jean-Pierre Bedoyan, Gabriel Bouchet, Christian Hamouy, Keiko Nakamura, Claude Ricou e Georges van Gucht (percussão). CD com duração de 43 minutos.

Nota sobre os autores

Ronan Gil (www.ronangil.com) - Mestre em Composition et Interprétation Musicale pela Université de Strasbourg (França). Possui Especialização em teclados de percussão pelo Conservatoire de Strasbourg (onde foi professor), estudando com Emmanuel Sejourné. É Bacharel em Percussão pela UNESP, recebendo o Prêmio de Excelência em Pesquisa. Trabalhou com Tom Mays, Antoine Spindler, Yves Kayser e Philippe Aubry. Fundou e integrou grupos como: Babel Trio, DUALpha, Ensemble Vertebrae Accroche Note, Texture Ensemble da Milano. Realiza estreias absolutas e primeiras audições nos continentes americano e europeu. Sua discografia inclui gravações com variadas formações. É professor de percussão do Instituto Federal de Educação, Ciência e Tecnologia de Goiás (IFG), membro do Impact(o) e líder do Núcleo de Excelência para o Ensino, Pesquisa e Performance em Percussão (N三P ${ }^{3}$ ).

Fernando Chaib (www.fernandochaib.com) - Doutor e Mestre em Música pela Universidade de Aveiro (Portugal) nas classes de Miquel Bernat e Evgueni Zouldilkine. É Bacharel em Percussão pela UNESP. Possui prêmios como solista e camerísta no Brasil, Portugal e Itália. Sua discografia inclui mais de dez CDs com diversas formações nos mais variados estilos. Atua nos continentes americano, europeu e asiático realizando estreias e primeiras audições. Fundou os grupos Simantra Grupo de Percussão e Grupo Durum Percussão Brasil. É professor convidado em festivais de música nos continentes americano e europeu. Atualmente é Professor Adjunto 
da Escola de Música da Universidade Federal de Minas Gerais (UFMG), atua no PPGMUS/UFMG, é membro do grupo Impact(o) e pesquisador do Núcleo de Excelência em Ensino, Pesquisa e Performance em Percussão $\left(\mathrm{N} \equiv \mathrm{P}^{3}\right)$.

Fabio Oliveira - Doutor pela Universidade da Califórnia (San Diego/EUA) sob orientação de Steven Schick, é Bacharel em Percussão pela UNESP e Mestre pela Universidade de Massachusetts (Amherst, EUA). Como solista e camerísta vem se apresentando nas Américas, Europa e Ásia. Colaborou/trabalhou com Steve Reich, Philippe Manoury, Helmut Lachenmann, David Lang, Roger Reynolds, Chaya Chernowin e Flo Menezes; gravou pelos selos Tzadik, Mode Records e New World Records, com destaque para o grupo redfishbluefish. Atua como professor em alguns dos principais festivais de música do Brasil. É Professor Associado da EMAC/Universidade Federal de Goiás (UFG), membro do Impact(o) e pesquisador do Núcleo de Excelência para o Ensino, Pesquisa e Performance em Percussão ( $N \equiv \mathrm{P}^{3}$ ). 